University of Nebraska - Lincoln

DigitalCommons@University of Nebraska - Lincoln

Faculty Publications: Department of Entomology

December 1984

\title{
Temperature-dependent Model for Sorghum Midge (Diptera: Cecidomyiidae) Spring Emergence
}

Frederick P. Baxendale

University of Nebraska-Lincoln, fbaxendale1@unl.edu

G. L. Teetes

Texas A \& M University

P. J. H. Sharpe

Texas A \& M University

Follow this and additional works at: https://digitalcommons.unl.edu/entomologyfacpub

Part of the Entomology Commons

Baxendale, Frederick P.; Teetes, G. L.; and Sharpe, P. J. H., "Temperature-dependent Model for Sorghum Midge (Diptera: Cecidomyiidae) Spring Emergence" (1984). Faculty Publications: Department of Entomology. 144.

https://digitalcommons.unl.edu/entomologyfacpub/144

This Article is brought to you for free and open access by the Entomology, Department of at DigitalCommons@University of Nebraska - Lincoln. It has been accepted for inclusion in Faculty Publications: Department of Entomology by an authorized administrator of DigitalCommons@University of Nebraska - Lincoln. 


\title{
Temperature-dependent Model for Sorghum Midge (Diptera: Cecidomyiidae) Spring Emergence
}

\author{
F. P. BAXENDALE, ${ }^{1}$ G. L. TEETES, AND P. J. H. SHARPE ${ }^{2}$ \\ Department of Entomology, Texas A\&M University, \\ College Station, Texas 77843
}

\begin{abstract}
Environ. Entomol. 13: 1566-1571 (1984)
ABSTRACT A temperature-dependent, two-component model, based on constant-temperature development data, was formulated which described the emergence of overwintered sorghum midges, Contarinia sorghicola (Coquillett) in the field. The first model component used a poikilotherm rate equation to predict emergence rates as a function of temperature. The second component distributed emerging adults over normalized time using a temperature-independent cumulative Weibull distribution. When coupled, components formed a temperature-dependent simulation model which described the spring emergence of overwintered midges from 1979 to 1982 . The model tended to predict emergence before it actually occurred in the field. This discrepancy was corrected by incorporating a $1.27-\mathrm{cm}$ precipitation delay factor which modified predicted rates to reflect the retarding effects of rainfall on daily emergence. Once precipitation delay was incorporated, the model very accurately predicted adult emergence during all 4 years.
\end{abstract}

SUCCESSFUL MANAGEMENT of the sorghum midge, Contarinia sorghicola (Coquillett), necessitates the use of integrated, multiple control tactics to maintain midge densities below economic levels (Young and Teetes 1977). A seasonal-dynamics model for use in monitoring midge generations in the field, scheduling sampling procedures, timing insecticide applications for maximum effectiveness, and evaluating new management strategies would be a valuable tool in the development of a comprehensive management program for the midge. Spring emergence, the first major seasonal event in the life history of the sorghum midge, must be accurately predicted if economically damaging midge generations are to be reliably forecast later in the season. Accordingly, an important part of the formulation of a seasonal-dynamics model involved construction of a temperature-dependent model which described the field emergence of overwintered midges.

The sorghum midge overwinters as a diapausing larva within sorghum, Sorghum bicolor (L.) Moench or johnsongrass, Sorghum halepense (L.) Pers. spikelets. Normally, these spikelets fall to the ground and become covered with litter or are disked into the soil along with plant residues (Baxendale and Teetes 1983a). Diapause termination and subsequent emergence of adult midges occurs in response to warm, moist soil conditions (Harding 1965). Baxendale and Teetes (1983b) conducted laboratory studies on diapause termination in sorghum midges and found that diapausing midges

' Present address: Dept. of Entomology, Univ. of Nebraska, Lincoln, NE 68583-0816.

' Biosystems Res. Div., Dept. of Industrial Engineering, Texas A\&M Univ., College Station, TX 77843. exposed to continuously moist conditions terminated diapause and emerged as adults when temperatures were in the range of 15 to $35^{\circ} \mathrm{C}$. Temperatures between 20 to $30^{\circ} \mathrm{C}$, however, were optimal for development and subsequent emergence.

In central Texas, emergence begins during the last part of April and is completed in the final weeks of June (Baxendale and Teetes 1983a). Commonly, however, there is considerable temporal variability in emergence periods among years. This variability is primarily a function of soil temperature and rainfall during the emergence period. In cooler years or when rainfall totals are high, emergence times can be delayed by 2 weeks or more (Baxendale and Teetes 1983a).

In the present study, the modeling approach of Sharpe and DeMichele (1977), as implemented by Wagner et al. (1984a,b) was used to construct a temperature-dependent model for the development and adult emergence of overwintered sorghum midges. The model was calibrated and validated using observed midge emergence in the field.

\section{Materials and Methods}

Constant-temperature Studies. Development of a temperature-dependent spring emergence model for the sorghum midge involved first determining the influence of temperature on diapause termination and postdiapause development (see Baxendale and Teetes 1983a). Environmental chambers were maintained at $10,15,20,25,30$, 35 , or $40^{\circ} \mathrm{C}$, with L:D 14:10 photoperiod. Sorghum spikelets collected in the field from a minimum of 100 midge-infested panicles were randomly mixed. 
Table 1. Summary statistics for adult emergence from diapausing sorghum midges maintained at selected constant temperatures

\begin{tabular}{cccc}
\hline \multirow{2}{*}{$\begin{array}{c}\text { Temp } \\
\left({ }^{\circ} \mathrm{C}\right)\end{array}$} & $\begin{array}{c}\text { Total no. } \\
\text { emerged } \\
\text { adults }\end{array}$ & $\begin{array}{c}\text { Median } \\
\text { (days) }\end{array}$ & $\begin{array}{c}\text { Mean (days) } \\
\pm \text { SEM }\end{array}$ \\
\hline 10 & 0 & - & - \\
15 & 2 & 67.0 & $76.0 \pm 9.00$ \\
20 & 171 & 35.7 & $38.5 \pm 0.75$ \\
25 & 299 & 19.4 & $21.1 \pm 0.38$ \\
30 & 155 & 17.7 & $19.4 \pm 0.53$ \\
35 & 7 & 33.0 & $33.6 \pm 4.20$ \\
40 & 0 & - & - \\
\hline
\end{tabular}

Six grams of these spikelets were placed between two layers of perlite within plastic containers sealed with clear plastic lids. Containers were assumed to contain equal numbers of diapausing larvae because of the randomization process. Spikelets in a total of 56 containers were saturated with distilled water (to expose diapausing larvae to free-water $[100 \% \mathrm{RH}]$ conditions) and were placed at each temperature. Adult emergence was recorded daily.

Emergence Studies in the Field. Emergence of overwintered sorghum midges was monitored from

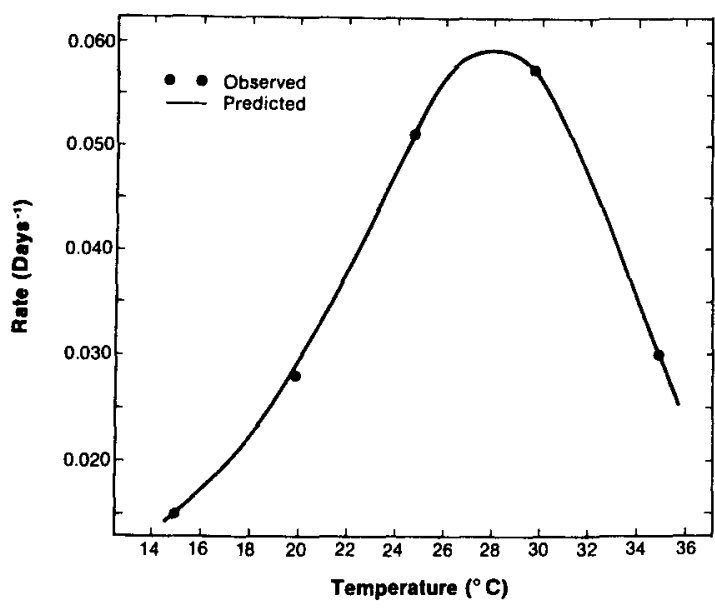

Fig. 1. Poikilotherm rate model (solid line) fitted to median emergence rates (dots) for diapausing sorghum midges at constant temperatures.

ber of insect species (Barfield et al. 1977, 1978, Palmer et al. 1981, Sharpe et al. 1981, Wagner et al. 1984a). The model is given by the nonlinear relationship:

$$
r(T)=\frac{R H O 25 \frac{T}{298.15} \exp \left[\frac{H A}{R}\left(\frac{1}{298.15}-\frac{1}{T}\right)\right]}{1+\exp \left[\frac{H L}{R}\left(\frac{1}{T L}-\frac{1}{T}\right)\right]+\exp \left[\frac{H H}{R}\left(\frac{1}{T H}-\frac{1}{T}\right)\right]}
$$

1979 to 1982 at the Texas A\&M University Plantation near College Station, using pyramid-shaped traps constructed of wooden frames covered with fine-mesh, saran screening (see Baxendale and Teetes 1983b). Adult midges emerging from spikelets in the soil were collected on Tree Tanglefoot ${ }^{\circledR}$ coated, acetate cylinders held within $437-\mathrm{ml} \mathrm{Ma}$ son jars atop each pyramid. Acetate cylinders were collected twice each week and the number of emerged adults recorded.

During all 4 years, soil temperature and rainfall were recorded at the emergence site. Temperature was measured continuously at the $10-\mathrm{cm}$ soil depth using a remote-point thermograph. Daily temperature means were calculated as the average of 12 2 -h readings. All emerged adults were from natural populations.

Analytical Procedures. Constant-temperature development data were used to formulate a twocomponent model of spring emergence. The first component utilized the poikilotherm rate equation developed by Sharpe and DeMichele (1977), and modified by Schoolfield et al. (1981) to describe median rates of emergence as a function of temperature. This model has been shown to describe accurately the development of an increasing num- where $r(T)=$ median development rate at temperature $T\left({ }^{\circ} \mathrm{K}\right) ; R=$ the universal gas constant (1.987 $\left.\mathrm{cal} \mathrm{deg}^{-1} \mathrm{~mol}^{-1}\right) ;$ RHO25 = development rate at $25^{\circ} \mathrm{C}$ assuming no enzyme inactivation $\left(\right.$ time $\left.^{-1}\right) ; H A=$ enthalpy of activation of the reaction that is catalyzed by a rate-controlling enzyme (cal $\mathrm{mol}^{-1}$ ); $T L=$ Kelvin temperature at which the rate-controlling enzyme is $1 / 2$ active and $1 / 2$ low-temperature inactive; $H L=$ change in enthalpy associated with low-temperature inactivation of the enzyme $\left(\mathrm{cal} \mathrm{mol}^{-1}\right) ; T H=$ Kelvin temperature at which the rate-controlling enzyme is $1 / 2$ active and $1 / 2$ high-temperature inactive; $H H=$ change in enthalpy associated with high-temperature inactivation of the enzyme ( $\mathrm{cal} \mathrm{mol}^{-1}$ ).

The second component of the spring emergence model distributed the emerging midge population over normalized time using a cumulative Weibull function (Wagner et al. 1984b). This function has the form:

$$
F(x)=1-\exp \left\{-[(x-\gamma) / \eta]^{\beta}\right\}
$$

where $F(x)=$ probability of complete development at normalized time $x$, and gamma $(\gamma)$, beta $(\beta)$, and eta $(\eta)$ are parameters to be estimated. 


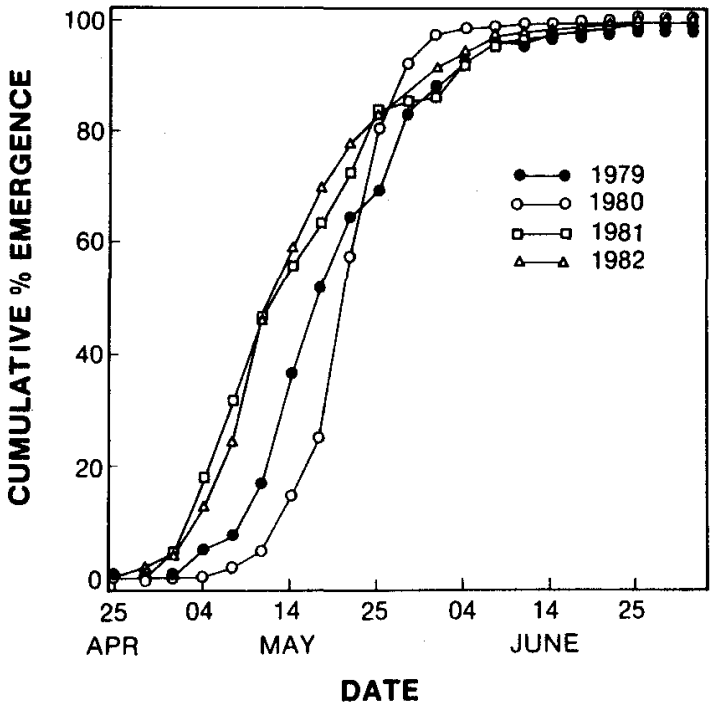

Fig. 2. Emergence of overwintered sorghum midges in the field during 1979-1982.

Gamma is the expected normalized time just before complete development of the first insect.

The computer programs (SAS) described by Wagner et al. $(1984 a, b)$ were used to calculate median emergence rates, select the most appropriate form of the poikilotherm rate equation (i.e., two, four, or six parameters), and determine parameter values for both the rate and distribution functions. A third program coupled the poikilotherm rate model with the cumulative Weibull distribution. Once coupled, these two components formed a temperature-dependent simulation model which distributed emerging adults over calendar time.

Temperature inputs to the simulation model consisted of mean daily $10-\mathrm{cm}$ soil temperatures starting 1 April. Since soil temperatures at this depth fluctuate little (ca. $1-3^{\circ} \mathrm{C}$ ) during a typical 24-h period (Baxendale 1983), single mean daily temperatures provided good estimates of soil temperatures during the day.

Validation of the spring emergence model involved comparisons of predicted and observed midge emergence in the field. Average absolute differences between simulated and observed cumulative percentages of emergence served as relative measures of model performance.
Table 3. Parameter estimates and asymptotic $95 \%$ confidence intervals of a cumulative Weibull distribution fitled to a standard normalized distribution for adult emergence of diapausing sorghum midges

\begin{tabular}{lrrrr}
\hline & Gamma $^{a}$ & Beta & \multicolumn{1}{c}{ Eta } & \multicolumn{1}{c}{$\boldsymbol{R}_{2}$} \\
\hline Parameter estimate & 0.6688 & 1.2599 & 0.4437 & 0.997 \\
95\% CI & \pm 0.0315 & \pm 0.1469 & \pm 0.0372 & - \\
\hline
\end{tabular}

a Gamma, beta, and eta are parameters estimated by the nonlinear regression procedure.

\section{Results and Discussion}

Constant-temperature Studies. Diapausing sorghum midges terminated diapause and emerged as adults when temperatures were between 15 and $35^{\circ} \mathrm{C}$ (Table 1). When temperatures were outside the optimum range of 20 to $30^{\circ} \mathrm{C}$, however, numbers of emerged adults declined sharply.

The relationship of sorghum midge development times to temperature was typical of poikilothermic organisms reared at different constant temperatures. At higher temperatures, the number of days required for median adult emergence decreased from 67.0 days at $15^{\circ} \mathrm{C}$ to 17.7 days at $30^{\circ} \mathrm{C}$. However, at $35^{\circ} \mathrm{C}$, median number of days until emergence was greater than at $30^{\circ} \mathrm{C}$, indicating that the thermal optimum is between 30 and $35^{\circ} \mathrm{C}$.

Temperature-dependent Model of Spring Emergence. When equation 1 was fitted to median emergence rates (Fig. 1), a four-parameter form of the poikilotherm model (with high-temperature inhibition) was selected by the computer program. In this form of the model, $T L$ and $H L$ of equation 1 are assigned the values 100 and $-100,000,000$, respectively. The fitted model provided a good description of the data $\left(R^{2}=0.998\right)$ and visual examination of the curve of rate versus temperature and Arrhenius plot (not shown) confirmed the appropriateness of the four-parameter form. Parameter estimates and their asymptotic 95\% confidence intervals are given in Table 2. While some parameters had wide confidence intervals, others were defined by a fairly narrow range. This condition is characteristic of nonlinear regression analyses (Gagne et al. 1982).

The cumulative Weibull distribution (eq. 2) was fitted to the standard normalized distribution of emergence times with good results $\left(R^{2}=0.997\right)$.

Table 2. Parameter estimates and asymptotic 95\% confidence intervals of the four-parameter poikilotherm model fitted to median development rates ( $1 /$ median time) for adult emergence of diapausing sorghum midges

\begin{tabular}{lrrrrr}
\hline \hline & RHO25 & HA & TH & HH & $R^{2}$ \\
\hline Parameter estimate & 0.0581 & $23,018.7$ & 303.22 & $67,548.43$ & 0.998 \\
$95 \%$ CI & \pm 0.0466 & $\pm 20,983.9$ & \pm 8.27 & $\pm 47,607.50$ & - \\
\hline
\end{tabular}

$R H O 25$, development rate at $25^{\circ} \mathrm{C}$ assuming no enzyme inactivation (time $e^{-1}$ ); $H A$, enthalpy of activation of the reaction that is catalyzed by a rate-controlling enzyme (cal mol$\left.{ }^{-1}\right) ; T H$, Kelvin temperature at which the rate-controlling enzyme is $1 / 2$ active and $1 / 2$ high-temperature inactive; $H H$, change in enthalpy associated with high-temperature inactivation of the enzyme (cal mol-1). 

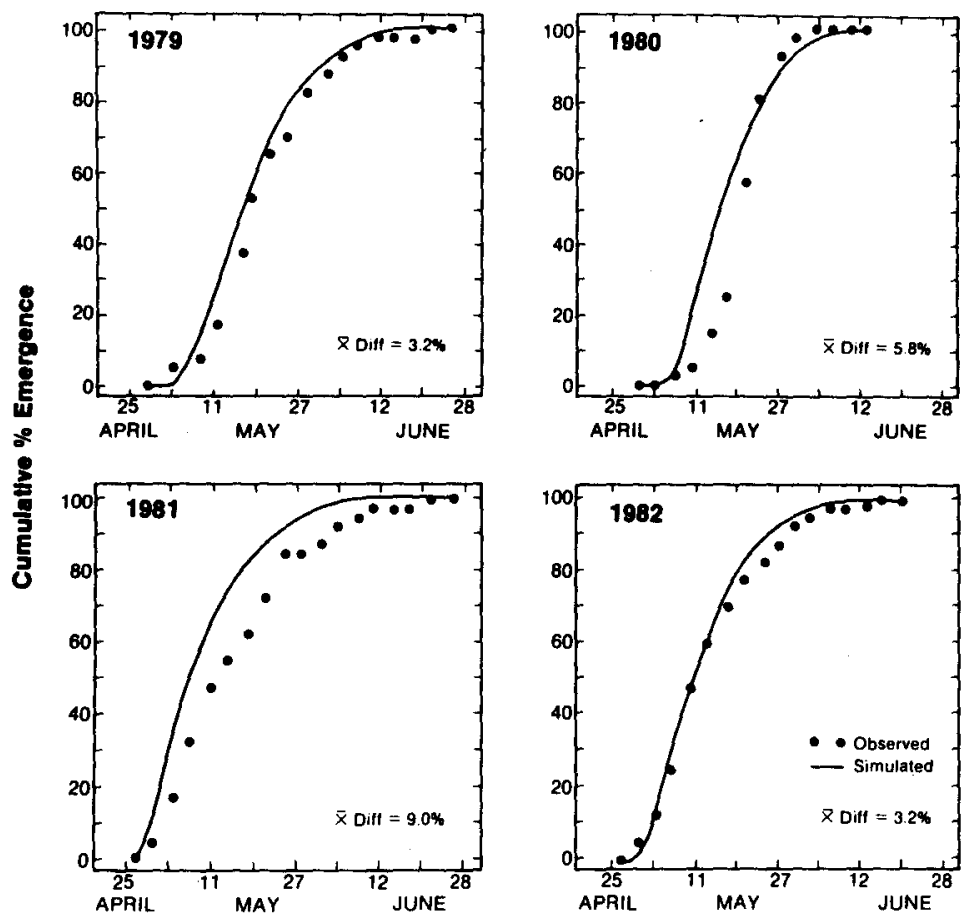

Fig. 3. Emergence of overwintered sorghum midges in the field (dots) during 1979-1982, compared with unadjusted model predictions (solid lines).

Date
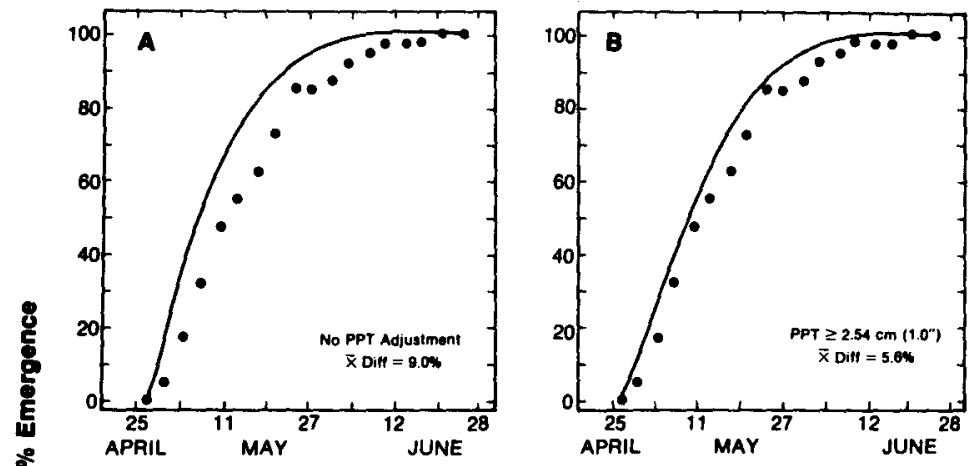

Fig. 4. Comparison of development predicted by model (solid lines), incorporating different precipitation (PPT) threshold levels to adjust for rainfall-induced delays in adult emergence, with observed emergence in the field (dots) during 1981. 

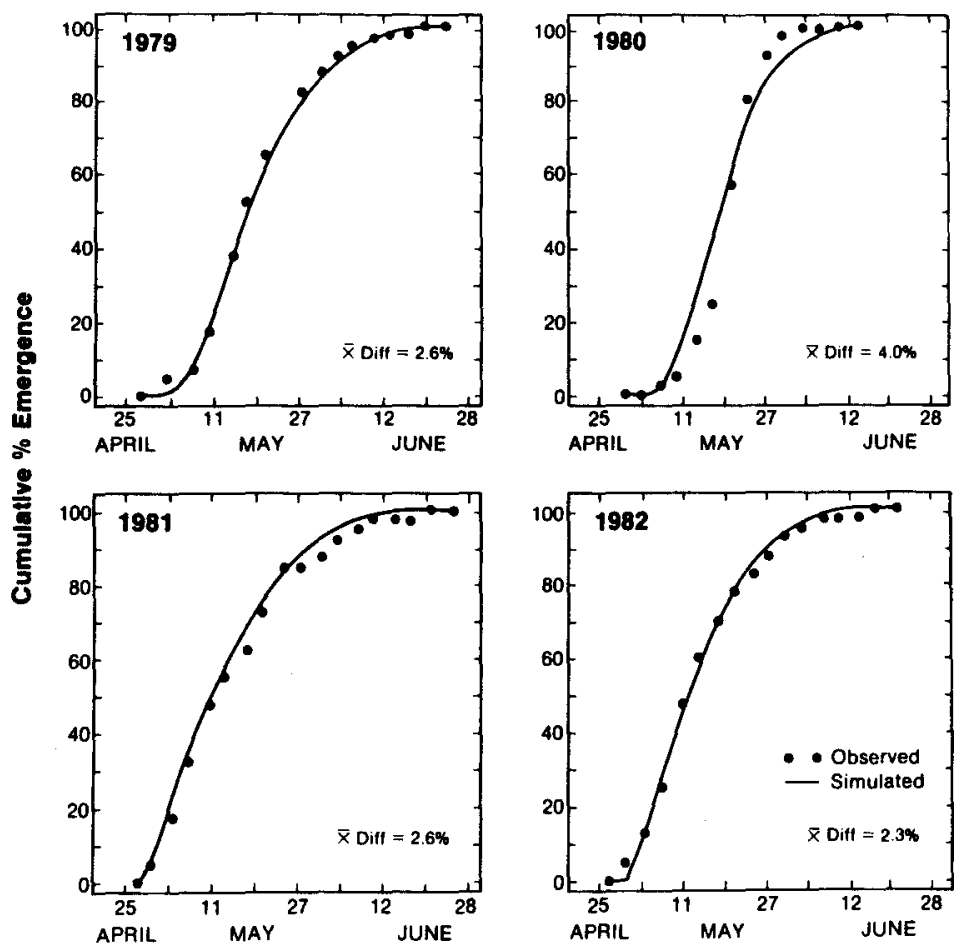

Fig. 5. Emergence of overwintered sorghum midges in the field (dots) during 1979-1982, compared with model predictions (solid lines) after incorporating $1.27-\mathrm{cm}$ precipitation threshold to adjust for rainfallinduced delays in adult emergence.
Parameter estimates and their asymptotic 95\% confidence intervals are presented in Table 3.

Spring Emergence and Model Validation. In all 4 years (1979-1982), the spring emergence of adult midges began in the last week of April and was completed during the final 2 weeks of June (Fig. 2). There was, however, considerable temporal variability among emergence periods across years. This variability had been previously shown to be a function of the soil temperatures and rainfall experienced during the emergence period (Baxendale and Teetes 1983b).

Model simulations were run, and predictions compared reasonably well with observed midge emergence in the field during all 4 years (Fig. 3). In 1979 and 1982, the mean absolute difference between simulated and observed cumulative percentage of emergence curves was only $3.2 \%$. In 1980 and 1981, however, the model ran several days early, with mean differences of 5.8 and $9.0 \%$, respectively.

In order to test the appropriateness of the 1 April starting date, model simulations were initiated earlier and later in the season. As the date of model-start moved away from 1 April, model performance slowly deteriorated. For example, when the 1982 simulation was initiated 1 January, the model predicted $50 \%$ emergence almost 8 days before it actually occurred. However, as the starting date for the simulation approached 1 April, model predictions gradually improved. Simulations initiated after 1 April were consistently late. The results of these simulations provided justification for the use of 1 April as the starting date for the spring emergence model in central Texas. In other regions, however, this initiation date would require modification to reflect local variations in emergence resulting from environmentally related differences in the sorghum midge's seasonal dynamics.

Examination of model predictions (Fig. 3), revealed a general tendency for the model to predict emergence before it actually occurred. This trend was particularly evident during the exceptionally rainy spring of 1981 (simulated $50 \%$ emergence on 6 May and observed $50 \%$ emergence on 12 May). Fisher and Teetes (1982) studied the influence of moisture on the emergence of nondiapausing midges and found that adult emergence was delayed by either natural rainfall or artificial panicle wetting during the expected emergerice period. Since rainfall had a similar delaying effect on the emergence of overwintered sorghum midges (Baxendale and Teetes 1983a), the possibility of improving the model by incorporating a precipitation adjustment factor was investigated. In a series of simulations, the model was used to define a precipitation threshold for emerging adults. This was accomplished by adjusting predicted emergence rates to reflect daily rainfall totals. On days when rainfall totals reached or exceeded a preset value $(0,2.54,1.91$, or $1.27 \mathrm{~cm}$ of rain), predicted emergence rates were set to 0 . This had the effect of slowing the model in direct proportion to the number of days reaching or exceeding the precipitation threshold.

Improvements in the model's performance as- 
sociated with increasing its sensitivity to rainfall (i.e., decreasing the precipitation threshold needed to slow the model) are shown in Fig. 4 for 1981. Mean absolute differences between simulated and observed cumulative percentages of emergence decreased from $9.0 \%$ when no precipitation adjustment was applied (Fig. 4A) to $2.6 \%$ when the precipitation adjustment was set at $1.27 \mathrm{~cm}$ (Fig. 4D). Lower threshold levels resulted in poorer model performance. Apparently, excessive amounts of rainfall (i.e., $\geq 1.27 \mathrm{~cm}$ ) during the postdiapause period retarded development, causing a shift toward longer development times in the overall midge population. Increased soil moisture during rainy periods may have inhibited continued development when oxygen deficits (or carbon dioxide excesses) developed as a result of reductions in the gaseous conductivity of the soil. Sharpe and $\mathrm{Hu}$ (1980) showed that the nitrogen level in the diet changed the rate of poikilotherm development and must be incorporated as an additional factor in the poikilotherm equation. From this study, soil oxygen level is also implicated as a factor modifying the equation.

When the $1.27-\mathrm{cm}$ precipitation threshold was incorporated into the model, simulations more accurately predicted spring emergence during all 4 years (Fig. 5). Not surprisingly, the years with the most rainfall showed the greatest improvements in model performance. For example, a total of 44.9 $\mathrm{cm}$ of rain fell during the 1981 emergence period and the mean absolute difference between simulated and observed cumulative percentages of emergence improved from 9.9 to $2.6 \%$. Lesser improvements were associated with model predictions during 1979,1980 , and 1982 , when there was only $28.2,16.6$, and $19.7 \mathrm{~cm}$ of rain, respectively. Based on the results obtained in these four simulations, the spring emergence model was judged suitable for incorporation into a larger seasonal dynamics model for the sorghum midge. However, with other soil types the precipitation threshold may need to be modified.

This study is the first in which the poikilotherm rate equation combined with a Weibull distribution has been used to formulate an insect development model that has been validated in the field. It is also the first time that the poikilotherm model has been applied to insect emergence from diapause. Finally, this is the first time that the poikilotherm equation has been used to model developmental processes in which lack of oxygen has been implicated as a factor reducing insect development rates.

\section{Acknowledgment}

Approved as TA19562 by Director, Texas Agric. Exp. Stn. This research was supported in part by grant AID/
DSAN/XII/G-0149 from the Agency for International Development, Project H-6216.

\section{References Cited}

Barfield, C. S., E. R. Mitchell, and S. L. Poe. 1978. A temperature-dependent model for fall armyworm development. Ann. Entomol. Soc. Am. 71: 70-74.

Barfield, C. S., P. J. H. Sharpe, and D. G. Bottrell. 1977. A temperature-driven developmental model for the parasite Bracon mellitor (Hymenoptera: Braconidae). Can. Entomol. 109: 1503-1514.

Baxendale, F. P. 1983. Modeling seasonal development of the sorghum midge, Contarinia sorghicola (Coquillett). Ph.D. dissertation, Texas A\&M University, College Station.

Baxendale, F. P., and G. L. Teetes. 1983a. Thermal requirements for emergence of overwintered sorghum midge (Diptera: Cecidomyiidae). Environ. Entomol. 12: 1078-1082.

1983b. Factors influencing adult emergence from diapausing sorghum midge, Contarinia sorghicola (Diptera: Cecidomyiidae). Ibid. 12: 1064-1067.

Fisher, R. W., and G. L. Teetes. 1982. Effects of moisture on sorghum midge (Diptera: Cecidomyiidae) emergence. Ibid. 11: 946-948.

Gagne, J. A., T. L. Wagner, P. J. H. Sharpe, and R. N. Coulson. 1982. Reemergence of Dendroctonus frontalis at constant temperatures. Ibid. 11: 12161222.

Harding, J. 1965. Ecological and biological factors concerning the sorghum midge in 1964. Tex. Agric. Exp. Stn. MP-773.

Palmer, W. A., D. E. Bay, and P. J. H. Sharpe. 1981. Influence of temperature on the development and survival of the immature stages of horn fly, Haematoba irritans irritans (L.). Prot. Ecol. 3: 299-309.

Schoolfield, R. M., P. J. H. Sharpe, and C. E. Magnuson. 1981. Nonlinear regression of biological temperature-dependent rate models based on absolute reaction-rate theory. J. Theor. Biol. 88: 719-731.

Sharpe, P. J. H., and D. W. DeMichele. 1977. Reaction kinetics of poikilotherm development. Ibid. 64: 649-670.

Sharpe, P. J. H., and L. C. Hu. 1980. Reaction kinetics of nutrition dependent poikilotherm development. Ibid. 82: 317-333.

Sharpe, P. J. H., R. M. Schoolfield, and G. D. Butler, Jr. 1981. Distribution model of Heliothis zea (Lepidoptera: Noctuidae) development times. Can. Entomol. 113: 845-856.

Wagner, T. L., H. Wu, P. J. H. Sharpe, R. M. Schoolfield, and R. N. Coulson. 1984a. Modeling insect development rates: a literature review and application of a biophysical model. Ann. Entomol. Soc. Am. 77: 208-225.

Wagner, T. L., H. Wu, P. J. H. Sharpe, and R. N. Coulson. 1984b. Modeling distributions of insect development time: a literature review and application of the Weibull function. Ibid. 77: 475-487.

Young, W. R., and G. L. Teetes. 1977. Sorghum entomology. Annu. Rev. Entomol. 22: 193-218.

Received for publication 16 April 1984; accepted 6 August 1984. 